\title{
THE CONDITIONS OF UNDERCUT BY SHAPING USING A ROUNDED PROFILE GEAR SHAPER CUTTER
}

\author{
Hodgyai Norbert, ${ }^{1}$ Tolvaly-Roșca Ferenc, ${ }^{2}$ Máté Márton ${ }^{3}$ \\ ${ }^{1}$ Sapientia Hungarian University of Transylvania, Faculty of Technical and Human Sciences, Department of \\ Mechanical Engineering, Târgu Mureș, Romania, hodgyai@ms.sapientia.ro \\ 2 Sapientia Hungarian University of Transylvania, Faculty of Technical and Human Sciences, Department \\ of Mechanical Engineering, Târgu Mureș, Romania, tferi@ms.sapientia.ro \\ ${ }^{3}$ Sapientia Hungarian University of Transylvania, Faculty of Technical and Human Sciences, Department of \\ Mechanical Engineering, Târgu Mureș, Romania, mmate@ms.sapientia.ro
}

\begin{abstract}
The present paper deals with the cases of undercut when not only the linear but the curved segment of the generatrix curve is also taken in consideration. The literature admits the approximation of the root fillet with a circular arc with a radius of $0,38 \mathrm{~m}$. In this paper, instead of this approximation, the real envelope realized by the rounded rack-head is computed. In analyzing the undercut there are two classical synthetic geometrical models supporting Litvin's general equations that describe the condition of avoiding the undercut: one for the linear and one for the rounded part of the generatrix. The scope of exact computing of the root fillet curve consists in optimizing the cutting toll tooth topland geometry to obtain the best rigidity. The numerically evaluated models allow us to conclude that profile shifting can be pushed below the undercut limits stated in the classical literature, without the appearance of the well-known fracture point on the meshed tooth profile.
\end{abstract}

Keywords: rack, profile parameters, meshing, root fillet, undercut.

\section{The importance of the tooth root fillet curve}

The exact geometric shape of the connecting gear teeth surfaces has been explored by many researchers, using analytical, synthetical, numerical and mixed investigation methods [1, 2, 3, 4]. The gear tooth root fillet curve usually is approximated by a circular arc [4, 5, 6], even in simulation tests. The root fillet shape, its accuracy and surface quality has a pronounced influence on lifetime, load capacity and the vibration chart of the gear-pair.

The joining between the tooth root fillet surface and the tooth flank is explained in a general sense in the existing literature. The accurate definition of the involute circle and the computing of its radius was firstly given by Szeniczei [7], for that particular case, when the involute circle is determined by the intersection point of the generating rack's active top line.

The root fillet curve is defined as the curve described by the intersection point of the cutting tool's edge and the tooth topland: in the case of a gear shaper comb it results as a knitted involute, while in the case of using a shaper cutter, a knitted epicycloid.

Litvin [2] defines the root fillet curve more accurately, considering the rounded end of the edge top. He states: the root fillet curve is an equidistant curve of that described by the center of the top fillet, where the distance is the radius.

Based on the results so far attained, a few questions are to be put. The first is how the root fillet and the flank involute joining point changes with the profile shifting. The comparison of the undercut geometry with the classic intersecting geometry is also of particular importance. Finally, the influence of the edge top fillet curve form on the root fillet form and implicitly on the dedendum strength and rigidity, is also of particular importance.

In the next the influence of a circular arc rounded edge-top shaper comb on the complete meshed toothflank form is studied. 


\section{The defining parameters of the ge- nerating rack}

This paper considers a generating rack having a DIN 867-1986 German standard defined basic profile. This standard defines the dedendum height in the interval $h_{P} \in(1,1 \div 1,4) m$. The present study is performed for a $h_{P}=1,25 \mathrm{~m}$ dedendum height.

Let's consider the rack profile presented in Figure 1. The topland fillet radius can be computed from two limiting conditions. The first one considers the whole top edge consisting of the junction of two symmetric circular arcs, while the second limits the circular portion of the edge occupying a maximum of $c_{0}^{*} m$ of the tooth height. Starting from these hypotheses and considering Figure 1 it can be written that

$$
r=\frac{m c_{0}^{*}}{\cos \alpha_{0}} \operatorname{tg}\left(\frac{\alpha_{0}}{2}+\frac{\pi}{4}\right)
$$

Using the computed radius value, the length of $E B$ results as:

$$
E B=E A=\frac{m c_{0}^{*}}{\cos \alpha_{0}}
$$

The length obtained is now compared with the half of the unrounded top edge length, by computing the difference between them:

$$
\delta=\frac{\pi m}{4}-m\left(h_{0}^{*}+c_{0}^{*}\right) \operatorname{tg} \alpha_{0}-\frac{m c_{0}^{*}}{\cos \alpha_{0}}
$$

For the standard rack parameter values $\delta>0$, thus the top edge consists of two circular arcs and their common tangent segment. the top edge is smoothed, no self-cutting exists.

The equation (1) returns the highest possible fillet radius value; thus, it is necessary to introduce

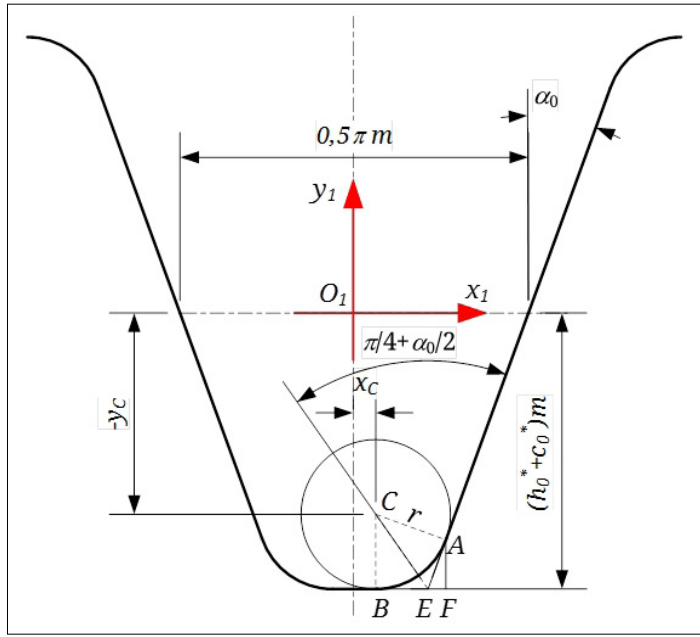

Figure 1. The rounded topland of the generating rack. a reducing factor $\psi, \psi \in[0,1]$. Using this, the value of the top fillet radius results as:

$$
r=\psi r^{*} m=\psi \frac{c_{0}^{*}}{\cos \alpha_{0}} \operatorname{tg}\left(\frac{\alpha_{0}}{2}+\frac{\pi}{4}\right) m
$$

Once the value of radius $r$ is set, the coordinates of center $C$ (1. ábra) are given by:

$$
\left\{\begin{array}{l}
x_{1}^{C}=m\left(\frac{\pi}{4}-\left(h_{0}^{*}+c_{0}^{*}\right) \operatorname{tg} \alpha_{0}-\frac{\psi r^{*}}{\cos \alpha_{0}}\right) \\
y_{1}^{C}=\left(\psi r^{*}-\left(h_{0}^{*}+c_{0}^{*}\right)\right) m
\end{array}\right.
$$

\section{The applied coordinate systems}

The relative kinematics of the cutting tool and meshed gear can be written with the use of the three frames presented in Figure 2.

The standing frame $O x_{0} y_{0}$ origin is set in the gearing pole. The frame $O_{1} x_{1} y_{1}$ is fastened to the generating rack, with axis $x_{1}$ incident to the pitch line. The centroid of the meshed gear is tangent to the axis $x_{0}$. Finally, the frame $O_{2} x_{2} y_{2}$ is attached to the meshed gear. Its rotation $\varphi$ determines the linear dispacement of the rack $r_{0} \varphi$ along axis $x$ [1].

Based on Figure 2 the equations of transformation can be written using the method presented in $[1,2,4,8]$ :

$$
\underline{\boldsymbol{r}_{2}}=\boldsymbol{M}_{21} \underline{\boldsymbol{r}_{1}}=\boldsymbol{M}_{20} \boldsymbol{M}_{01} \underline{\boldsymbol{r}_{1}}
$$

As shown in Figure 2

$$
\begin{gathered}
\boldsymbol{M}_{21}=\left(\begin{array}{ccc}
\cos \varphi & -\sin \varphi & a_{13}(\varphi) \\
\sin \varphi & \cos \varphi & a_{23}(\varphi) \\
0 & 0 & 1
\end{array}\right), \\
a_{13}(\varphi)=-r_{0}(\sin \varphi-\varphi \cos \varphi)+m \xi \sin \varphi \\
a_{23}(\varphi)=r_{0}(\cos \varphi+\varphi \sin \varphi)+m \xi \cos \varphi
\end{gathered}
$$

\section{The equation of meshing}

The equation of meshing can be written based on [2]. Position vectors $\mathbf{r}_{1}$ and $\mathbf{r}_{2}$ both pointing to the common point of element 1 (the rack) and element 2 (the shaped gear), position vector A starting from the origin of frame 1 and pointing to the origin of frame 2 , are connected in the following vectorial equation:

$$
\begin{aligned}
& \boldsymbol{v}_{1}^{(12)}=\boldsymbol{v}_{1}^{(1)}-\boldsymbol{v}_{1}^{(2)}= \\
= & \omega_{2} r_{0} \boldsymbol{i}_{\mathbf{1}}-\boldsymbol{\omega}_{2} \times \boldsymbol{r}_{2}= \\
= & \omega_{2} r_{0} \boldsymbol{i}_{\mathbf{1}}-\boldsymbol{\omega}_{2} \times\left(\boldsymbol{r}_{2}-\boldsymbol{A}\right)
\end{aligned}
$$

Setting the angular velocity $\omega_{2}=1 \mathrm{rad} / \mathrm{s}$ and performing the vector calculus results in:

$$
\underline{\boldsymbol{v}}_{1}^{12}=\left(\begin{array}{c}
-y_{1}-m \xi \\
x_{1}+r_{0} \varphi \\
0
\end{array}\right)
$$




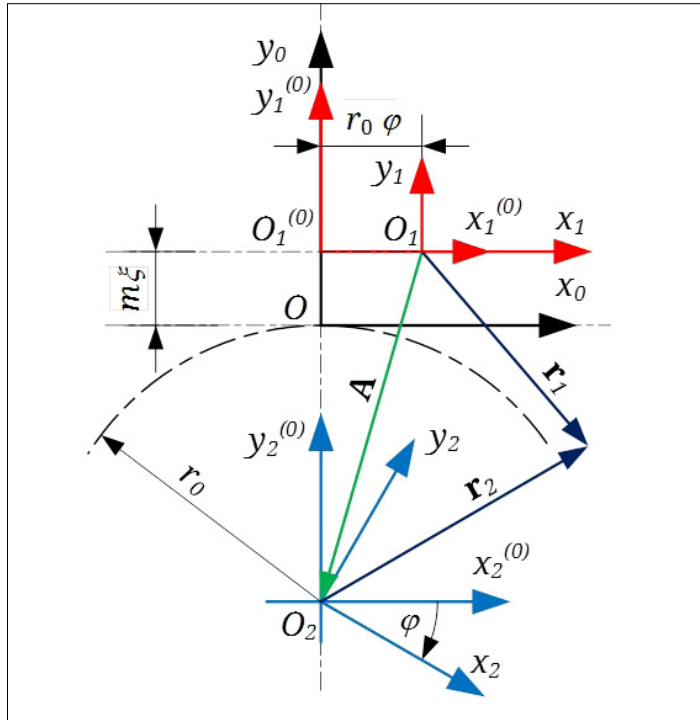

Figure 2. The applied coordinate systems.

\section{The complete generating curve}

The complete generating curve results from merging the straight segment, and the top fillet arc. The straight segment's parameter is a linear distance taken along the tooth height, while that of the arc is the central angle. Thus:

$$
\begin{gathered}
\left\{\begin{array}{r}
x_{1 e}(u)=\frac{\pi m}{4}+u \operatorname{tg} \alpha_{0}, \\
y_{1 e}(u)=u \\
u \in\left[-\left(h_{0}^{*}+c_{0}^{*}\right), h_{0}^{*}\right]
\end{array}\right. \\
\left\{\begin{array}{l}
x_{1 k}(u)=x_{1}^{C}+r \cos \left(\alpha_{0}+u\right) \\
y_{1 k}(u)=y_{1}^{C}-r \sin \left(\alpha_{0}+u\right)
\end{array}\right. \\
u \in\left[0, \frac{\pi}{2}-\alpha_{0}\right]
\end{gathered}
$$

The coordinates of the normal vectors can by written using the geometrical peculiarities shown in Figure 1:

$$
\underline{\boldsymbol{n}}_{1 e}=\left(\begin{array}{c}
\cos \alpha_{0} \\
-\sin \alpha_{0} \\
0
\end{array}\right) ; \underline{\boldsymbol{n}}_{1 e}=\left(\begin{array}{c}
\cos \alpha_{0} \\
-\sin \alpha_{0} \\
0
\end{array}\right)
$$

\section{Solving the equation of meshing}

The solution of the equation of meshing will be written only for the circular arc - it is well known that the manifold of the straight edge parts will mesh an involute curve. The position of the involute, in concordance with the tool- gear relative position seen in Figure 2, where the pole of gearing $P$ is the midpoint of the generating edge, can be easily computed using the geometric dependences proven in [1, 7]:

$$
\begin{aligned}
& \left\{\begin{array}{l}
x_{2}^{e v}\left(\varphi_{1}\right)=r_{b}\left(\sin \left(\varepsilon+\varphi_{1}\right)-\varphi_{1} \cos \left(\varepsilon+\varphi_{1}\right)\right) \\
x_{2}^{e v}\left(\varphi_{1}\right)=r_{b}\left(\cos \left(\varepsilon+\varphi_{1}\right)+\varphi_{1} \sin \left(\varepsilon+\varphi_{1}\right)\right)
\end{array}\right. \\
& \varepsilon=\frac{\pi}{2 z}-2 \frac{\xi}{z} \operatorname{tg} \alpha_{0}-i n v \alpha_{0}
\end{aligned}
$$

Here must be emphasized the fact that the angular parameter $\varphi$ of the rolling and $\varphi_{1}$ parameter of the involute (13) are in linear dependence.

Using expressions (5), (9) and (12), the equation of meshing becomes:

$$
\begin{aligned}
& \left(y_{1}^{C}+m \xi\right) \cos \left(u+\alpha_{0}\right)+ \\
& +\left(x_{1}^{C}+r_{0} \varphi\right) \sin \left(u+\alpha_{0}\right)=0
\end{aligned}
$$

The complete solution of the homogeneous trigonometric equation above is:

$$
u(\varphi)=-\alpha_{0}-\operatorname{arctg} \frac{y_{1}^{C}+m \xi}{x_{1}^{C}+r_{0} \varphi}+k \pi, k \in \mathbb{Z}
$$

The solution (15) of the meshing equation applies to the complete circle whose arc forms a part of the topland edge. Therefore, only the points of the real fillet portion must be considered, in order to obtain the real root fillet curve. Let us denote with $g(\varphi)$ the argument of the arc tangent function. It is easy to observe than $\mathrm{g}(\varphi)$ admits a vertical asymptote for

$$
\varphi_{\text {krit }}=\frac{x_{1}^{C}}{r_{0}}
$$

The real root fillet results for

$u(\varphi)=\left\{\begin{array}{l}-\arctan (g(\varphi))-\alpha_{0}+\pi, \text { if } \varphi \leq \varphi_{\text {krit }} \\ -\arctan (g(\varphi))-\alpha_{0}, \quad \text { if } \varphi>\varphi_{\text {krit }}\end{array}\right.$

\section{Numerical simulation}

The analytical form of the root fillet curve is obtained from the computing of the matrix equation (6) where parameter $u$ of $\underline{\mathbf{r}}_{1}$ vector is replaced by expression (16). Due to the pretty complicated form of the equation, we omit to write them in their explicit form. The analytical forms were proven using the Mathcad computing environment, for a gear with teeth number, $z_{2}=18$ and module $m=5 \mathrm{~mm}$.

Figure 3 shows the meshed circles and the root fillet curve obtained for a relative radius factor $\psi=0.79$. This corresponds to an edge top fillet radius of $r=1.5$. The relative position of the curves lets us conclude that when decreasing the edge top fillet radius, the root fillet becomes steeper and sharper. This statement is proven through the graphical comparison of tooth flanks obtained with different rack edge profiles set for different 
relative radius factors and profile shifting parameters.

Although according to classical theory [7] the limit of the undercut occurs for $\xi=-0.053$, the flank meshing was simulated for $\xi \in\{-0.15 ;-0.2$; $-0.25 ;-0.3 ;-0.35 ;-0.4\}$ éprofile shifting values, for $\psi=0.79$ and $\psi=0.1$ relative edge top fillet radius.

The results are represented on Figures 4, 5, 6, 7 and 8.

Figure 4. shows clearly that an undercut caused by an appropriate edge top fillet radius does not appear as sharply as the literature [7] specifies it. It must be also emphasized that setting the cutting rack near the limit of the undercut, the involute segment of the tooth flank shortens significantly; the contact ratio strongly reduces due to this. Although stress concentration in the root fillet is avoided. For a comparison, let's consider the profiles shown in Figure 5 Here the rack is set on the limit of the classic undercut, but despite this, only a slight, acceptable undercut results.

It can be clearly seen in Figures 6,7 and 8 that the radius of curvature has a significant effect on the root fillet shape. If using a larger edge top fillet radius, the undercut occurs in a much duller, acceptable form. Although the decreasing of the involute segment length leads to a smaller contact ratio, in some cases the need for setting the tool under the limit of undercut can appear. In such cases, computing and setting the appropriate val-

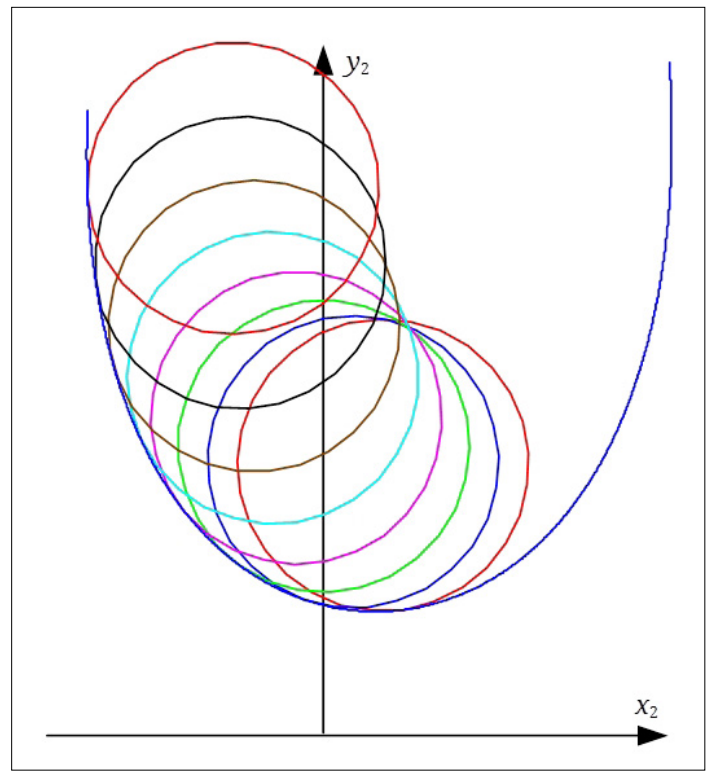

Figure 3. The root fillet and the meshed circle manifold.

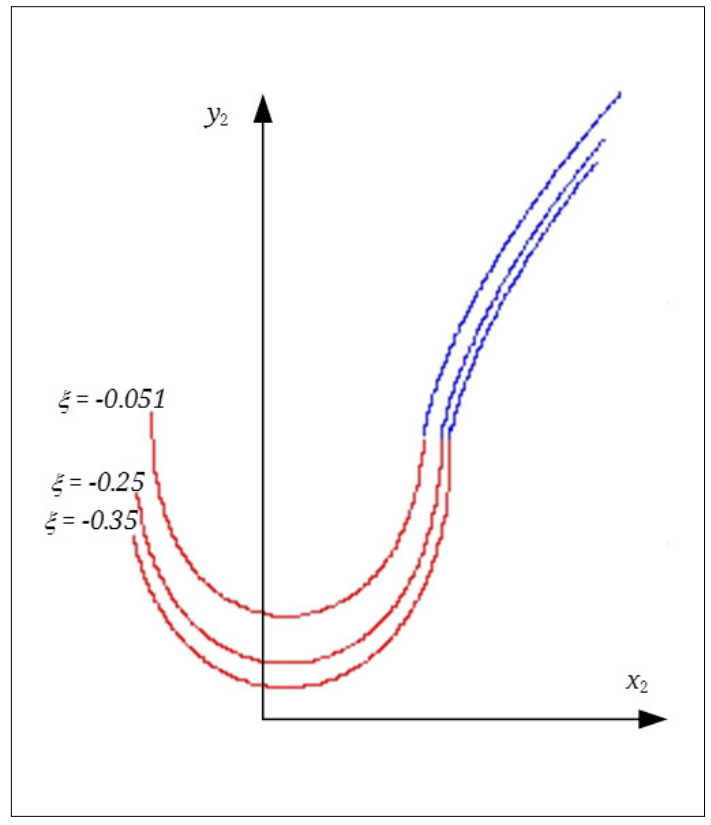

Figure 4. Connection of the tooth fillet and the involute in the case of using an $r=1.5 \mathrm{~mm}$ top fillet edge.

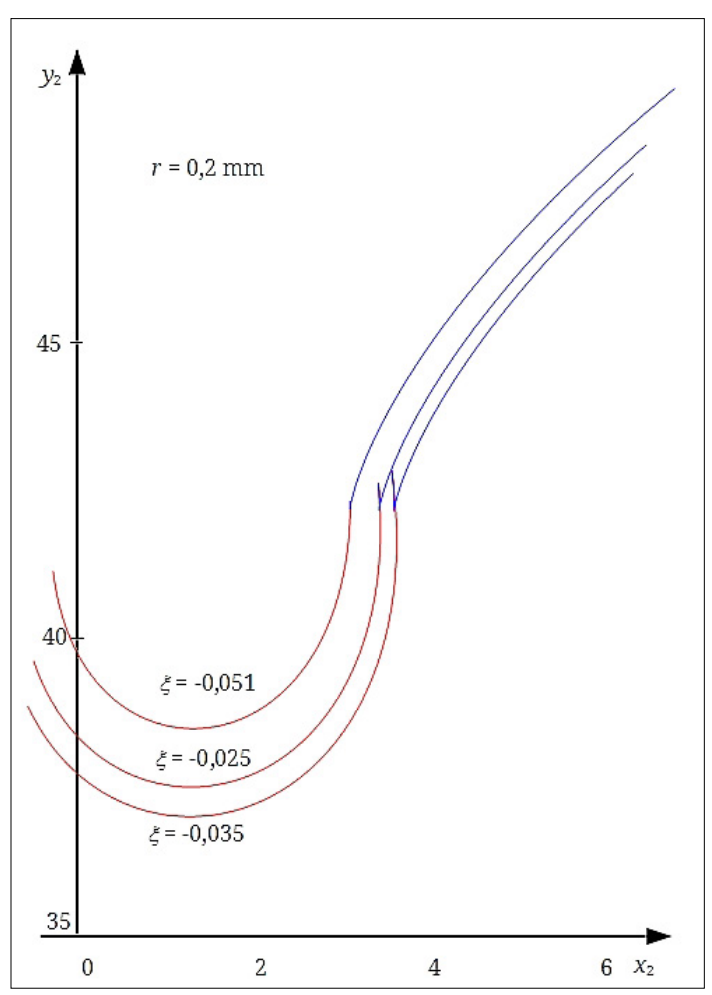

Figure 5. Connection of the tooth fillet and the involute in the case of using an $r=0.2 \mathrm{~mm}$ top fillet edge. 


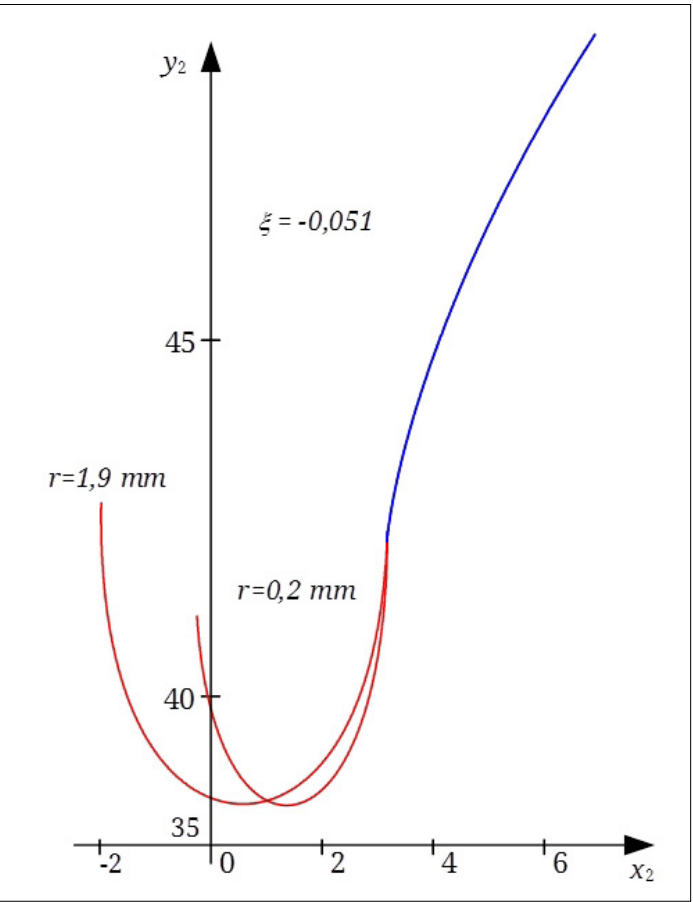

Figure 6. The variation of the root fillet with the edge top fillet radius when the rack is set on the classical limit of undercut.

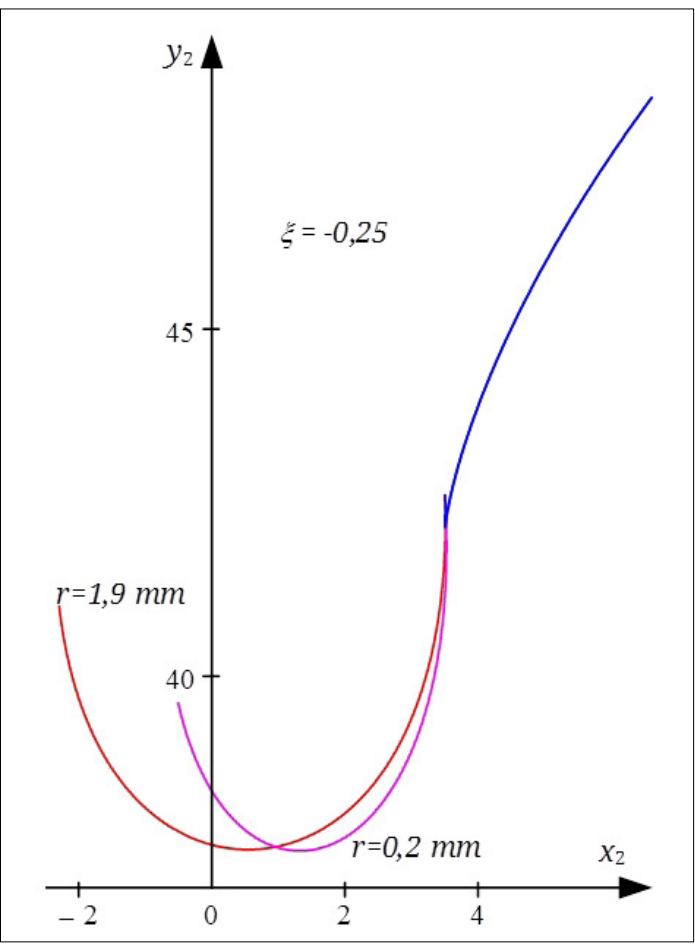

Figure 7. The dependence of the shape of the root fillet on the edge top fillet radius for $\xi=-0.25$.

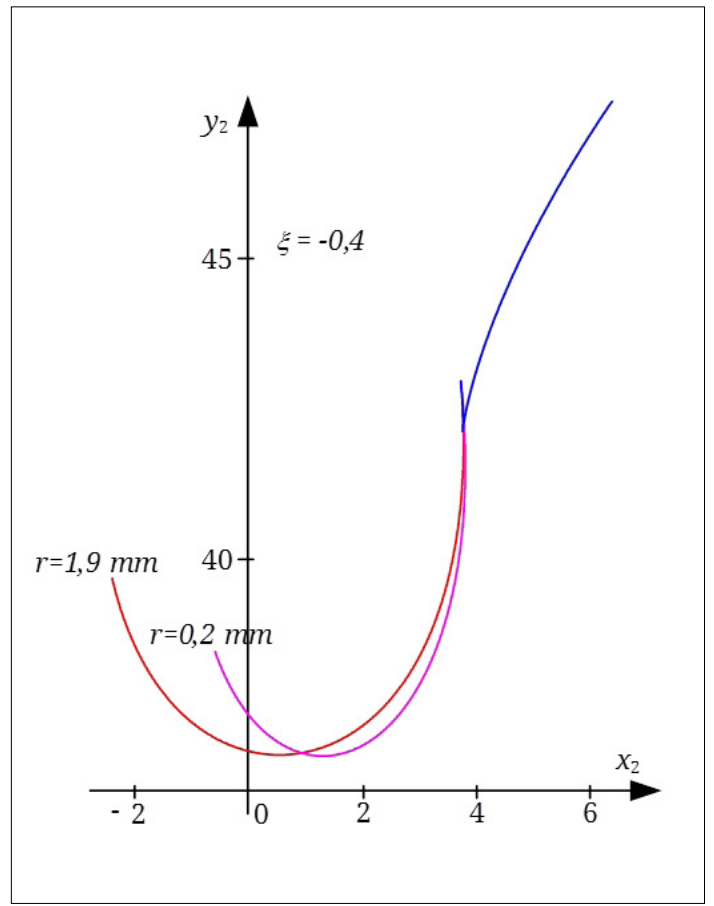

Figure 8. The dependence of the shape of the root fillet on the edge top fillet radius for $\xi=-0.40$.

ue of the edge top fillet radius on the cutting tool becomes of utmost importance. Next, an alternative pure geometrical method will be presented, useful for identification of singularities.

\section{The geometrical modelling of the undercut}

A significant breakthrough in the theory of gearing was realized by Litvin [2], who identified the boundary of the undercut as the position where singular points appear on the meshed (or cut) profile. His idea is a great geometric-kinematic observation, because in this case the derivatives $\dot{x}, \dot{y}$ of the meshed curve, written in the parametric form are zero, thus the contact point velocity along the profile is also zero, which contradicts the law of gearing. Based on these, using the condition of identity of the contacting point absolute velocities, it can be written that

$$
\begin{aligned}
& \boldsymbol{v}_{t}^{(1)}+\boldsymbol{v}_{r}^{(1)}=\boldsymbol{v}_{t}^{(2)}+\boldsymbol{v}_{r}^{(2)} \Rightarrow \\
& \boldsymbol{v}_{r}^{(2)}=\boldsymbol{v}^{(12)}+\boldsymbol{v}_{r}^{(1)}
\end{aligned}
$$

Equation (17) allows the limitino of the cutting tool profile from the condition $\mathbf{v}_{\mathrm{r}}^{(2)}=0$, avoid- 
ing the need for computing the envelope equations.

The synthetic geometric method proposed in this paper allows equations to be written without the use of the system of equations (12), deduced in [2].

The geometric dependencies are illustrated separately for both the straight and curved segments of the complete generating curve.

Let us observe the velocity vectors given in an arbitrary point of the linear edge segment, as shown in Figure 9.

The point $M$ situated on the straight segment of the rack becomes a contact point when the rack is translated along the $\mathrm{x}$ axis with distance $r_{0} \varphi$ while the normal defined in it passes through the pole of gearing $P$. Now that we consider the feed velocity of the rack defined, let us denote it $\mathbf{v}_{\mathrm{t} 1}$. Knowing that the trajectory of the point $M$ is the contacting line which is also the support of the absolute velocity vector of $M$, and knowing that the relative velocity vector is a tangent to the profile, its value can be easily computed. Relative to the standing frame it can be written that

$$
\left(\begin{array}{l}
-v_{r 1} \sin \alpha_{0} \\
-v_{r 1} \cos \alpha_{0}
\end{array}\right)+\left(\begin{array}{c}
v_{t 1} \\
0
\end{array}\right)=\left(\begin{array}{c}
v_{a b s z} \cos \alpha_{0} \\
-v_{a b s z} \sin \alpha_{0}
\end{array}\right)
$$

After elementary computation results

$$
v_{r 1}=\frac{v_{t 1}}{\sin \alpha_{0}}
$$

With this, and also taking in consideration expressions (9) and (10), the condition $\mathbf{v}_{12}+\mathbf{v}_{\mathrm{r} 1}=0$ turns into the following system of equations:

$$
\left\{\begin{array}{c}
-(u+m \xi)-r_{0} \sin ^{2} \alpha_{0}=0 \\
\frac{\pi m}{4}+u \operatorname{tg} \alpha_{0}+r_{0} \varphi-r_{0} \sin \alpha_{0} \cos \alpha_{0}=0
\end{array}\right.
$$

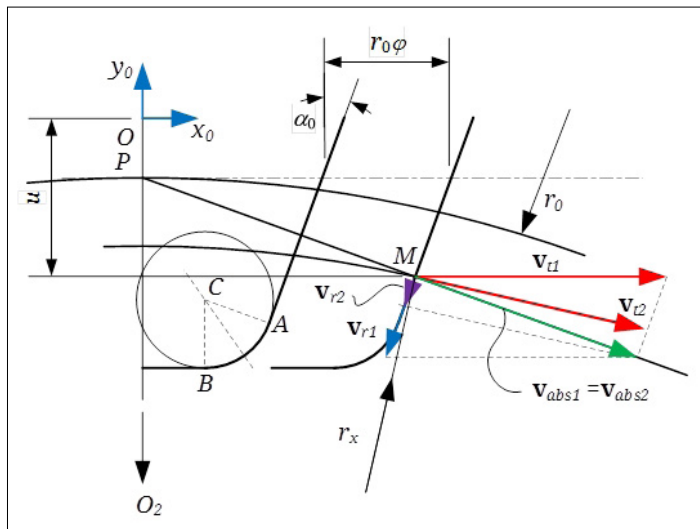

Figure 9. The velocity vectors on the straight segment of the generating profile, in the instantaneous contacting point.
First equation of system (20), for a given profile shifting value, returns the value of $u$ for which the undercut occurs. Particularizing this first equation for the case of $\xi=0, u=-h_{0}^{*} m$ results the critical number of teeth on the limit of undercut [7]. The second equation returns the value of the rolling angle for which the singularity on the meshed tooth profile occurs.

The velocity parallelogram in an arbitrary point of the circular segment of the rack profile is shown in Figure 10.

While considering the positive translation of the rack, defined by rolling angle $\varphi$ the center of the fillet arc arrives in $C_{1}$ whose abscissa is

$$
x_{1}^{C_{1}}=x_{1}^{C}+r_{0} \varphi
$$

With this, angle $\psi_{1}$ can be primed from triangle $P F C_{1}$

$$
\operatorname{tg} \psi_{1}=\frac{x_{1}^{C}+r_{0} \varphi}{-y_{1}^{C}-m \xi}
$$

Thus, the value of angle $\vartheta$ defined by the radius $\mathrm{O}_{2} \mathrm{M}_{1}$ and the centerline $\mathrm{OO}_{2}$ becomes computable by

$$
\operatorname{tg} \vartheta=\frac{x_{1}^{C}+r_{0} \varphi+r \sin \psi_{1}}{r_{0}+y_{1}^{C}+m \xi+r \sin \psi_{1}}
$$

Using the expression above, the expression of the radius $O_{2} M_{1}$ in dependence with $\vartheta(\phi)$ takes the following form:

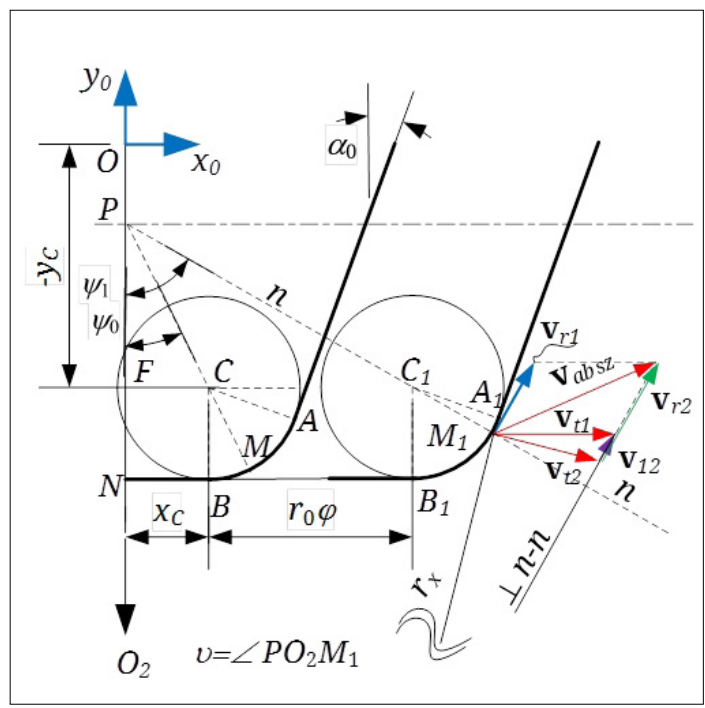

Figure 10. The velocity vectors on the circular segment of the generating profile, in the instantaneous contacting point. 


$$
O_{2} M_{1} \equiv r_{x}=\frac{x_{1}^{C}+r_{0} \varphi+r \sin \psi_{1}}{\sin \vartheta}
$$

The transport velocity vector of the $2^{\text {nd }}$ element of the technological gearing pair, the cut gear, using expressions (23) and (24) can be written as

$$
\underline{v}_{t 2}=\frac{r_{x}}{r_{0}}\left(\begin{array}{c}
\cos \vartheta \\
-\sin \vartheta \\
0
\end{array}\right)
$$

Next the $v_{r 1}$ relative velocity vector's expressions must be written. The location changing of the contacting point along the profile is determined by the variation of angle $\psi_{1}$ The absolute value of the relative velocitv vector equals the elementary variation of arc $\overparen{M M_{1}}$ :

$$
\begin{aligned}
& v_{r 1}=r \frac{d \psi_{1}}{d t}= \\
& \frac{-\left(y_{1}^{C}+m \xi\right) r_{0} \varphi}{\left(y_{1}^{C}+m \xi\right)^{2}+\left(x_{1}^{C}+r_{0} \varphi\right)^{2}} \omega_{2}, \omega_{2}=1 \frac{r a d}{\mathrm{~s}}
\end{aligned}
$$

Thus, the contacting point's relative velocity on the tooth profile of the $2^{\text {nd }}$ element becomes:

$$
\underline{v}_{r 2}=\left(\begin{array}{l}
r_{0} \\
0 \\
0
\end{array}\right)-\frac{r_{x}}{r_{0}}\left(\begin{array}{c}
\cos \vartheta \\
-\sin \vartheta \\
0
\end{array}\right)+v_{r 1}\left(\begin{array}{c}
\cos \psi_{1} \\
\sin \psi_{1} \\
0
\end{array}\right)
$$

Finally, let us remark that parameter $u$ of the fillet arc and parameter $\psi_{1}$ depending on rolling parameter $\varphi$ fulfill the condition below:

$$
u=\frac{\pi}{2}-\alpha_{0}-\psi_{1}
$$

Inserting this expression in (27) and zeroing the first two projections of the relative velocity vector results in the $u$ value for which the singularity appears, and the $\varphi$ rolling angle value where it occurs.

\section{Conclusion}

The rounded edge top of the cutting tool, under a convenient fillet radius, produces a more advantageous root fillet than the theoretical sharp edge top.
Graphical simulations have shown that the undercut limit can be pushed beyond the limit defined by the classical theory.

The geometrical conditions of singularities appearance allowed us to conclude that the form of the edge top fillet significantly influences the form of the root fillet and the moment of occurring of singularities.

\section{Acknowledgment}

The research partially published in this paper was realized with the support of the Transylvanian $\mathrm{Mu}-$ seum Society. Authors use this opportunity to express their thankfulness.

\section{References}

[1] Hollanda D.: Bazele așchierii și generării suprafețelor. Vol. 2. Editura Universității „Petru Maior” Tîrgu-Mureș, 1996. 160-162.

[2] Litvin F. L.: A fogaskerékkapcsolás elmélete. Müszaki Könyvkiadó, Budapest, 1972.

[3] Máté M.: Hengeres fogaskerekek gyártószerszámai. Erdélyi Múzeum-Egyesület, Kolozsvár, 2016. https://doi.org/10.36242/mtf-12

[4] Balajti Zs.: Examination and adjustment of the bearing pattern in case of helicoid drives. In: $8^{\text {th }}$ CIRP Conference on High Performance Cutting, Budapest, Hungary, June 25-27. 2018. Procedia CIRP. 77. (2018) 267-270.

[5] Mohammad Q. A., Muhsin J. J.: Analytical Solution of Bending Stress Equation for Symmetric and Asymmetric Involute Gear Teeth Shapes with and without Profile Correction. Innovative Systems Design and Engineering Vol. 3. Nr. 6. 2012 (2018). 19-30.

[6] Zhou Yuansheng, WuYuanhang, Wang Liming, Tang Jinyuan, Ouyang Hongwuab: A new closedform calculation of envelope surface for modelling face gears. In: Mechanism and Machine Theory, 137. (2019) 211-226.

[7] Szeniczei L.: Általános fogazás. Nehézipari Műszaki Könyvkiadó, Budapest, 1955.

[8] Radzewich S. P.: Gear Cutting Tools. CRC Press, NY. 2010. 